\title{
Forecasting capelin Mallotus villosus biomass on the Newfoundland shelf
}

\author{
Keith P. Lewis*, Alejandro D. Buren, Paul M. Regular, Frances K. Mowbray, \\ Hannah M. Murphy
}

Northwest Atlantic Fisheries Centre, Fisheries and Oceans Canada, Science Branch, East White Hills Road, PO Box 5667, St. John's, NL A1C 5X1, Canada

\begin{abstract}
Forage fish play a central role in marine ecosystems, acting as a trophic link between plankton and larger marine species. They also contribute to global economies by directly and indirectly supporting commercial and recreational fisheries. Managing forage fish is problematic due to their high spatial-temporal variation in biomass and strong responses to environmental variability. A variety of mechanisms have been proposed to explain variation in capelin Mallotus villosus biomass, a keystone forage fish in the Northwest Atlantic, including factors influencing cohort strength such as larval abundance and larval food (i.e. Pseudocalanus spp.) availability. Alternately, pre-spawning mortality of capelin may be regulated by the timing of the retreat of sea ice $\left(t_{\text {ice }}\right)$ via its effects on the spring bloom and the availability of food (e.g. Calanus spp.) for adult capelin, or by the condition of adult capelin the previous fall. Here, we used a Bayesian approach in a multimodel inference framework to assess support for a series of hypotheses explaining the population dynamics of capelin. The most parsimonious model included larval abundance, $t_{\text {ice }}$ and capelin condition in the fall, and explained $68 \%$ of the variance in capelin biomass. These results are consistent with much of the literature that suggests capelin in the Northwest Atlantic are driven by bottom-up forces. This model allows us to produce forecasts of capelin biomass 1-2 management cycles in advance, which will be a valuable contribution to the management of this forage fish species.
\end{abstract}

KEY WORDS: Capelin · Fisheries management - Biomass · Cohort strength · Adult mortality · Bayesian $\cdot$ Multimodel inference $\cdot$ Northwest Atlantic

\section{INTRODUCTION}

Forage species are an important component of global fisheries (FAO 2006, Alder et al. 2008) and also occupy a critical position in marine food webs, linking the energy produced by plankton to large-bodied fishes, birds, and mammals. A primary challenge for fisheries managers and policymakers is to determine a level of fishing on forage fish that accounts for the important ecological role that they play in the larger marine environment (Alheit \& Niquen 2004, Pikitch et al. 2012). However, determining a sustainable catch level is often hampered by a limited ability to

\footnotetext{
*Corresponding author: keith.lewis@dfo-mpo.gc.ca
}

predict biomass of forage fish for 3 fundamental, but not mutually exclusive, reasons: (1) forage fish biomass can be difficult to quantify because it exhibits large spatial variation; (2) forage fish are prone to booms and busts (i.e. abundances change rapidly in response to environmental conditions), with large associated impacts on dependent organisms; and (3) forage fish exhibit strong population responses (i.e. changes in abundance and/or distribution) to environmental variability (Hilborn \& Walters 1992, Pikitch et al. 2012).

Capelin Mallotus villosus is a keystone forage fish species in the North Atlantic ecosystem and is an

(C) Fisheries and Oceans Canada 2019. Open Access under Creative Commons by Attribution Licence. Use, distribution and reproduction are unrestricted. Authors and original publication must be credited.

Publisher: Inter-Research · www.int-res.com 
important commercial fishery species. It is a small, short-lived, shoaling species that exhibits 'boom-bust' population dynamics and is characterized by a large proportion of spent adults experiencing post-spawning mortality (Templeman 1948, Shackell et al. 1994). The 3 largest capelin stocks are in the Barents Sea, off the coast of Iceland, and on the Newfoundland and Labrador (Canada) continental shelf (Carscadden \& Vilhjálmsson 2002). For the Barents Sea capelin stock, an assessment model framework using Bifrost/ Captool is used for advice on total allowable catch (TAC) (Gjøsæter et al. 2015). The model uses a fall (September) acoustic survey to predict spawning stock biomass (SSB), and to estimate capelin maturity, growth, and natural mortality (including predation by immature cod on pre-spawning capelin; ICES 2016b). The Iceland capelin stock is surveyed twice each year (fall and winter). A provisional TAC is set after the fall acoustic survey of the immature portion of the stock with the final TAC based on a model that accounts for the uncertainties in the fall and winter acoustic surveys and predation from cod, haddock, and saithe (ICES 2016a). Both the Barents Sea and Iceland capelin stocks have a biomass limit ( $\left.B_{\text {lim }}\right)$ and the fishery will be closed if the estimated SSB is less than the $B_{\text {lim }}$. Acoustic surveys for both the Barents Sea and Iceland capelin stocks are assumed to cover the entire distributional range of capelin.

The capelin stock on the Newfoundland and Labrador (Canada) continental shelf (North Atlantic Fisheries Organization [NAFO] Div. 2J3KL capelin stock; hereafter the Newfoundland capelin stock) has decreased dramatically from a high of 6 million tonnes (Mt) in the late 1980s to 0.02-0.06 Mt in 1990-1991 with minimal recovery over the past 28 yr (DFO 2018, Buren et al. 2019). The decline in capelin biomass coincided with a regime shift in the NW Atlantic ecosystem during the late 1980s and early 1990s (DeYoung \& Rose 1993, Pedersen et al. 2017). Major changes in the biology and ecology of capelin occurred after the collapse of the capelin stock, including delayed and protracted spawning, as well as declines in somatic condition, size at maturity (Carscadden et al. 2001, Nakashima \& Wheeler 2002), and proportion of older age classes (DFO 2018). In contrast to the other 2 major capelin stocks where topdown (i.e. predation) forces are considered major drivers of capelin survival, the collapse of the Newfoundland capelin stock in the early 1990s is hypothesized to have been due to bottom-up processes that affected the recruitment and survival of capelin (Buren et al. 2014a, Obradovich et al. 2014, Murphy et al. 2018). In the NW Atlantic, capelin are a key driver in the biomass dynamics of Atlantic cod Gadus morhua (Buren et al. 2014b), linked to changes in fecundity of Northwest Atlantic harp seals Pagophilus groenlandicus (Stenson et al. 2016), and are key prey for Greenland halibut Reinhardtius hippoglossoides (Dwyer et al. 2010), whales (Gulka et al. 2017, J. Lawson \& G. Stenson unpubl. data), and seabirds (Davoren \& Montevecchi 2003, Montevecchi 2007, Buren et al. 2012). Given the importance of capelin in food web dynamics and their currently depressed population state, understanding the mechanisms that regulate capelin biomass is vital to understanding broader ecosystem changes in the NW Atlantic. A mechanistic understanding of capelin regulation is also essential to predict capelin biomass to improve the provision of Fisheries and Oceans Canada's (DFO) science advice for capelin management and to allow for an ecosystem-based approach to management for the many predators that rely on capelin as a primary food source (Link 2002, Pikitch et al. 2004).

A variety of mechanisms operating at different life stages may regulate the Newfoundland capelin stock. Capelin cohort strength (or year class strength) has been related to larval survival (Leggett et al. 1984, Dalley et al. 2002, Murphy et al. 2018), and larval survival in the first 2 wk was related to onshore winds from 1974-1990 (Carscadden et al. 2000). Post1990, capelin cohort strength was related to larval abundance of the same cohort and density of their preferred larval prey, Pseudocalanus spp. (Murphy et al. 2018). While cohort strength is set early in the life history of capelin, capelin experience mortality throughout their life cycle which may modulate cohort strength. Pre-spawning mortality of capelin is regulated by seasonal sea ice dynamics, putatively via its effects on the spring bloom, which in turn influences the dynamics of Calanus finmarchicus, the main prey of adult capelin (Buren et al. 2014a). Match-mismatch dynamics between $C$. finmarchicus and pre-spawning capelin was hypothesized to influence the condition and mortality of capelin (Buren et al. 2014a). The relationship between sea ice retreat and capelin biomass is not linear but rather domeshaped, with an early or late sea ice retreat related to low capelin abundance due to a potential mismatch with $C$. finmarchicus, while a medium sea ice retreat may result in high capelin abundance due to a potential match with the $C$. finmarchicus bloom. Finally, the fall somatic condition of pre-spawning capelin, prior to overwintering, may influence their survival potential during the spring pre-spawning mortality bottleneck (Buren et al. 2014a). 
The strength of ecological relationships can change over time (Taylor et al. 2002); this is true for the Newfoundland capelin stock with neither the relationship between capelin cohort strength and onshore winds (Murphy et al. 2018) nor the relationship between capelin biomass and sea ice (F. K. Mowbray \& A. D. Buren unpubl. data) producing robust predictions in recent years. Further, a single variable is unlikely to capture the multiple, highly stochastic processes that influence capelin demography from emerging larvae to the pre-spawning adult stage. For example, larval abundance does not capture years of extremely low or high cohort strength (Murphy et al. 2018). Having only a partial understanding of the regulatory mechanisms underlying capelin population dynamics has limited our ability to forecast capelin biomass. Nearterm forecasting of capelin biomass would be of immediate benefit for the management of this stock (Payne et al. 2017, Dietze et al. 2018).

Here, we expand upon previous work by testing and comparing a series of hypotheses regarding the bottom-up regulation of capelin using a Bayesian approach in a multimodel inference framework. Specifically, we re-examined the influence of cohort strength (larval abundance and availability of preferred larval prey; Murphy et al. 2018) and pre-spawning adult mortality (sea ice dynamics and its link to spring feeding; Buren et al. 2014a) on the biomass of the Newfoundland capelin stock. We also considered fall condition of capelin, due to its potential impact on survival during the spring pre-spawning mortality bottleneck (Table 1). Further, we tested combinations of these factors to assess their relative importance in describing capelin stock biomass. The models were developed with the aim of producing forecasts of capelin biomass 1-2 management cycles in advance.

Table 1. Variables used to explain capelin biomass with the associated duration of the time series, the lag in years of the time series used in the analysis, and range of values. Reference column provides references with the most complete or original description for deriving these variables. $t_{\text {ice }}$ t timing of the retreat of sea ice; DOY: day of the year

\begin{tabular}{|c|c|c|c|c|}
\hline Variable & $\begin{array}{l}\text { Time series } \\
\text { duration }\end{array}$ & Lag & Range & Reference \\
\hline Capelin biomass (kt) & $1982-2017$ & 0 & $22-6000$ & Mowbray $(2013,2014)$ \\
\hline $\begin{array}{l}\text { Larval abundance } \\
\left(\text { larvae } \mathrm{m}^{-3}\right)\end{array}$ & 2001-2017 & 2 & $578-3770$ & Murphy et al. (2018) \\
\hline $\begin{array}{l}\text { Zooplankton abundance } \\
\text { (larval prey; no. } \mathrm{m}^{-2} \text { ) }\end{array}$ & 1999-2016 & 2 & $3738-27659$ & Pepin et al. (2017) \\
\hline$t_{\text {ice }}(\mathrm{DOY})$ & $1969-2018$ & 0 & $39-98$ & Buren et al. (2014a) \\
\hline $\begin{array}{l}\text { Capelin condition } \\
\text { (unitless) }\end{array}$ & 1995-2017 & 1 & $0.97-1.03$ & Le Cren (1951) \\
\hline
\end{tabular}

\section{MATERIALS AND METHODS}

\subsection{Study area and data series}

The dominant bathymetric feature on the Newfoundland and Labrador (NL) shelf is the Grand Banks (Fig. 1) while the Labrador Current, which brings cold, fresh water south from the Arctic, is the dominant physical oceanographic feature. Sea ice coverage is seasonal and coverage is related to the variation in the interannual strength of the Labrador Current (Rice 2002). The retreat of the sea ice in spring is strongly correlated with the timing of the spring phytoplankton bloom (Wu et al. 2007).

\subsubsection{Capelin biomass}

We used the capelin stock biomass index derived from DFO's spring acoustic survey off the eastern coast of NL (1982-1992, 1996, 1999-2005, 2007-2015, 2017; Mowbray 2013, 2014). This index covers the core of the spring distribution area $\left(46-50^{\circ} \mathrm{N}\right)$ of the Newfoundland capelin stock (predominately age-2 capelin; Fig. 1), and covers the area from the Newfoundland coastline to the $500 \mathrm{~m}$ depth contour along the shelf edge. Due to incomplete coverage, this survey is considered an index and not an estimate of total biomass. Acoustic backscatter from the calibrated $38 \mathrm{kHz}$ frequency of a Simrad EK500/EK60 echosounder system was integrated along parallel transects within depth-delimited strata. Targeted fishing with a Campelen 1800 shrimp trawl was used to verify species composition and obtain biological samples. The capelin spring acoustic survey estimates capelin abundance that is converted to biomass. Monte Carlo simulations were performed to estimate $95 \%$ confidence intervals (Mowbray 2013). Note that 2018 capelin biomass estimates are currently unavailable.

\subsubsection{Cohort strength indices}

We used DFO's larval emergence index from Bellevue Beach, Trinity Bay, NL (2001-2018). Larval sampling was conducted in this area based on earlier work that found capelin beach spawning was synchronous across 


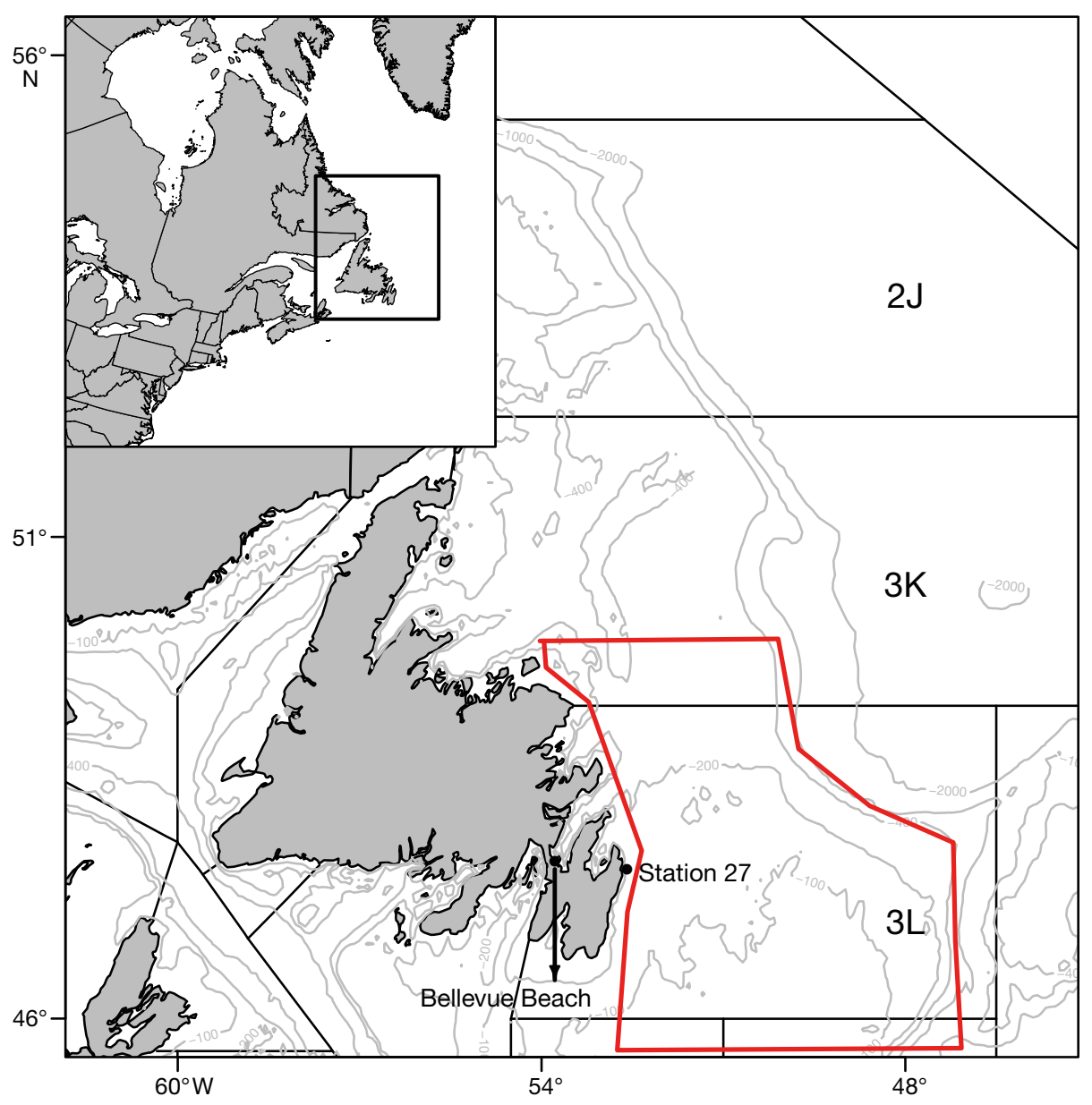

Fig. 1. Capelin stock area, North Atlantic Fisheries Organization Divisions 2J3KL. Red polygon: area covered by the spring acoustic survey. The locations of Bellevue Beach and Stn 27, where capelin larval abundance and Pseudocalanus spp. densities, respectively, were collected, are indicated. Bathymetry contours are shown in $\mathrm{m}$

Newfoundland beaches (Frank \& Leggett 1981b, Nakashima 1996). The methods for larval emergent sampling are described elsewhere (Nakashima \& Mowbray 2014, Murphy et al. 2018). Briefly, emergent capelin larvae were sampled from the onset to the end of emergence, which can last up to 6 wk. Capelin larval sampling occurred by boat and consisted of surface tows of 10 min duration at 2.1 knots every 24$48 \mathrm{~h}$ during daylight at 5 stations using a $270 \mu \mathrm{m}$ mesh size net with a $0.75 \mathrm{~m}$ diameter ring with an attached General Oceanic flowmeter. Capelin larval samples were preserved in $5 \%$ formalin and seawater and were enumerated in the laboratory. Annual larval production $\left(\mathrm{m}^{-3}\right)$ was estimated using the trapezoidal integration method (Murphy et al. 2018).

To calculate interannual larval prey density, we used DFO's Atlantic Zone Monitoring Program (AZMP) estimates of Pseudocalanus spp. abundance from the high frequency sampling site, Stn 27, from 1 June1 October for the years 1999-2017 (Fig. 1) (Pepin et al. 2017). Although there is an AZMP sampling line closer to Trinity Bay (the Bonavista Line), this line is not sampled as often as Stn 27. Wilson et al. (2018) found that Pseudocalanus spp. abundance is strongly correlated $(r=0.75)$ between Stn 27 and the Bonavista Line so we used Stn 27 as a proxy for Pseudocalanus spp. production in Trinity Bay.

\subsubsection{Adult mortality indices}

To determine the annual timing of the seasonal sea ice retreat $\left(t_{\text {ice }}\right)$, digital versions of weekly regional ice charts for the Newfoundland region were obtained from the Canadian Ice Service (http://iceweb1.cis. ec.gc.ca/Archive/page1.xhtml). For each week for the years 2003-2017, we converted the ice chart date into the day of the year (DOY) and then determined the most southern position of the sea ice from $55^{\circ} \mathrm{N}$ (Hamilton Bank) to the Grand Banks of Newfoundland 
$\left(43^{\circ} \mathrm{N}\right)$. Following Wu et al. (2007) and Buren et al. (2014a), the DOY of the most southerly position within a year was defined as the start of the sea ice retreat. Ice that was not part of the main ice pack, such as ice trapped in bays around the island of Newfoundland or in Lake Melville in Labrador, was not considered when determining the value of $t_{\text {ice }}$. To determine if $t_{\text {ice }}$ was further influenced by large ice sheets floating free of the ice pack, we visually assessed all of the ice maps. Weeks with sheets of ice south of the main pack were removed from the analysis if they influenced the value of $t_{\text {ice. }}$.

We calculated the fall somatic condition (hereafter, fall capelin condition) of age-1 $(n=9151)$ and age- 2 ( $\mathrm{n}=9974$ ) capelin from 1998-2017 based on the length and weight of capelin sampled during the DFO fall (October-December) multi-species bottom-trawl survey (DFO 2018). The relative condition of capelin was estimated as a relative condition factor:

$$
K_{r}=W / \hat{W}
$$

where $W$ is the weight of the individual capelin and $\hat{W}$ is the predicted body weight from a log-log length-weight relationship (Le Cren 1951). Capelin $<80 \mathrm{~mm}$ in length or $<2 \mathrm{~g}$ in weight were considered age-0 fish that had not yet undergone metamorphosis and were removed from the analyses.

\subsection{Data analysis}

\subsubsection{Models}

Due to the large interannual variation in capelin biomass, all analyses were performed on the natural logarithm of capelin biomass. To describe the variation in capelin biomass, we developed a suite of models using variables that were previously identified as important for Newfoundland capelin population dynamics: larval abundance and larval prey densities (cohort strength; Murphy et al. 2018), as well as $t_{\text {ice }}$ and fall capelin condition (adult mortality; Buren et al. 2014a; Table 2; Fig. 2 shows an overview of the temporal relationships amongst the variables). There were 2 cohort strength models: one that related capelin biomass to larval abundance (CSO) and a second model that related capelin biomass to larval abundance and larval prey densities (CS1). Both of the cohort strength models were linear and lagged by $2 \mathrm{yr}$ in order to compare survivors of the same cohort (Murphy et al. 2018). There were also 2 pre-spawning adult mortality models. One related capelin biomass to the $t_{\text {ice }}$ in the spring of the current year (dome-shaped relationship based on Buren et al. 2014a; see model AM0 in Table 2 for model structure). A second model (AM1) included $t_{\text {ice }}$ and the fall

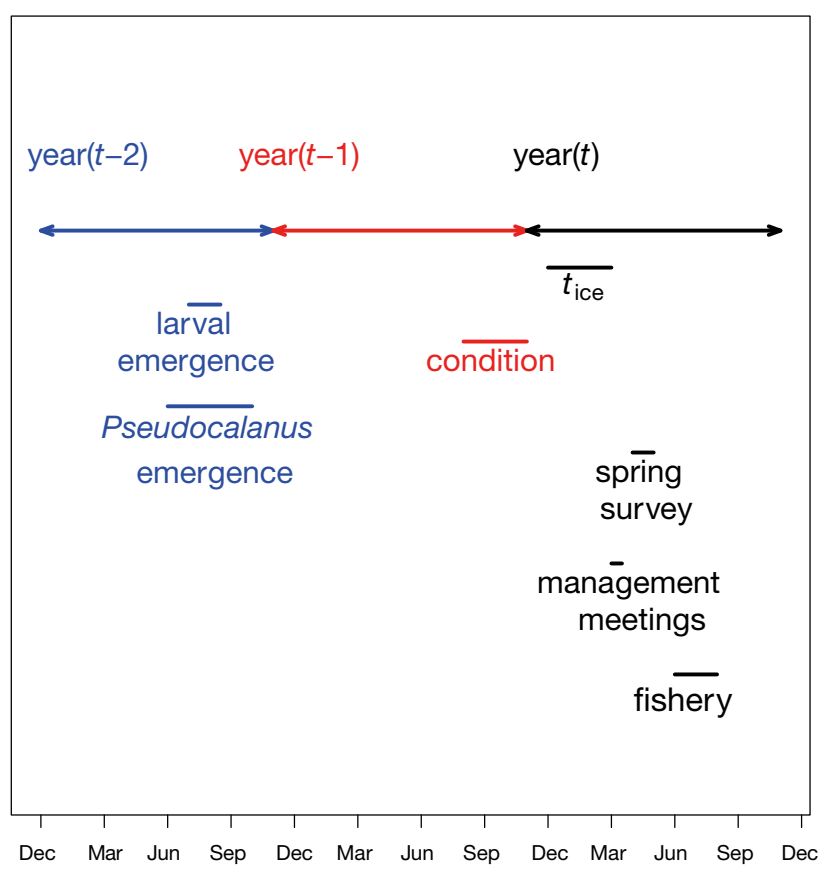

Fig. 2. Overview of the temporal relationship among the explanatory variables (see Table 1), capelin biomass generated from the acoustic spring survey as well as associated activities, i.e. management meetings and the capelin fishery. Double headed arrows: extent of a calendar year; bars above text: extent of the given variable or activity; arrow and text for years match the variables and activities that occur in that year; $t_{\text {ice: }}$ timing of the retreat of sea ice 
capelin condition (i.e. capelin sampled the previous fall; linear relationship). The cohort strength + adult mortality models (CSAM1, CSAM2, CSAM3) combined the influence of capelin larval abundance with one or both proxies for adult mortality, i.e. $t_{\text {ice, }}$ and fall capelin condition. We did not include larval prey densities in the combined models as preliminary results suggested this variable had poor explanatory power.

We fitted the models from Murphy et al. (2018; CS0) and Buren et al. (2014a; AM0) for these data series in order to compare the more complex models to the original work. Note, however, that the results from CS0 and AM0 are not directly comparable to the original work presented in Murphy et al. (2018) and Buren et al. (2014a) as both studies used different portions of the available time series than used in the current analysis. An information-theoretic approach requires the same data to be used across all models and, as such, our analyses were limited by the shortest time series, which was the capelin larval surface tows. Models assumed a normal error structure and we used an identity link.

\subsubsection{Model implementation}

All of the explanatory variables were normalized prior to analysis (Zuur et al. 2013) except for $t_{\text {ice }}$ (see Table 2), which could not be normalized because the resulting negative values would make the resulting dome-shaped model biologically uninterpretable. Instead, $t_{\text {ice }}$ was divided by 100 in order to make the scale similar to the other variables. Following Zuur et al. (2010), we conducted an exploratory data analysis prior to the formal data analysis. Scatterplots were used to visualize relationships and assess possible collinearity amongst variables, but we detected no significant issues. Parameters and associated credible intervals were estimated in a Bayesian framework. We present capelin biomass forecasts and their associated uncertainty in the form of prediction intervals.

Prior distributions. For the intercept and all other variables where the associated parameters were slopes (i.e. larval abundance, larval prey density, and fall condition), we used uninformative, normal priors (mean $=0, \mathrm{SD}=100$; Zuur et al. 2013). For the error term, we used an uninformative uniform prior (range $=0-100)$. For the $t_{\text {ice }}$ maximal rate of increase parameter (see Table $2 ; \delta$ ), we used uninformative priors based on the uniform distribution $(\min .=0$, max. = 100; Bolker 2008). This prior was bounded by zero so that the dome would only have positive values of capelin biomass. For $t_{\text {ice }}$ width $(\eta)$, we used the uniform distribution (min. $=0$, $\max .=3.65$; Bolker 2008). This prior was bounded by zero and 3.65 so that the results applied to the days in a calendar year.

Model convergence. We used 3 chains in the Markov chain Monte Carlo process with a burn-in of 1000 iterations (Zuur et al. 2013). Subsequently, we started each analysis using a thinning rate of 3 and 2000 iterations for each posterior distribution. To assess convergence, we used the Gelman and Rubin $\hat{\mathrm{R}}$ convergence diagnostic (Gelman \& Rubin 1992) and visually inspected the mixing of the chains. If convergence was in doubt, we used the previous number of iterations as a burn-in and then ran 300000 iterations with a burn-in of 100000 and a thinning rate of 50. Otherwise, we proceeded with the analysis. We found no evidence of autocorrelation among the chains by visually assessing autocorrelation plots.

\subsubsection{Model comparison and selection}

The parsimony of this set of models was assessed using the deviance information criterion (DIC), which is appropriate for comparing models within the Bayesian framework (Spiegelhalter et al. 2002, Zuur et al. 2013, Hooten \& Hobbs 2015). We also calculated the mean square prediction error (MSPE) in order to compare the predictive ability of each model (Gelman et al. 2014, Hobbs et al. 2015). A comparison of the information criteria among a set of models reveals the most parsimonious model but this may simply indicate the best in a set of poor models (Mac Nally et al. 2018). Commonly used measures of model fit, such as $\mathrm{R}^{2}$ for ordinary least squares (OLS) regression or an examination of the confidence intervals of the parameter estimates, alleviates this problem. However, the $\mathrm{R}^{2}$ for OLS regression is not applicable in a Bayesian framework. In response, Gelman et al. (2018) proposed an $\mathrm{R}^{2}$ that is appropriate for Bayesian analyses. We calculated this 'Bayesian $\mathrm{R}^{2 \prime}$ for all of the above models.

\subsubsection{Model validation and sensitivity}

To validate the models, we performed 3 steps. First, following Zuur et al. (2013), we calculated a dispersion parameter as a test for overdispersion. Second, we plotted the Pearson residuals of each model against the covariates to determine if there were any issues with non-linearity. We found no problems with 
overdispersion or non-linearity. Finally, the leaveone-out jack-knife method, a type of cross-validation, has been shown to provide an unbiased estimate of model performance, i.e. how well the model predicts new observations with data that are independent of those data used to estimate the model's parameters (Olden et al. 2002). Essentially, we sequentially left out the value of capelin biomass for a given year, recalculated the model, and used the model to predict capelin biomass for the left out year. We then compared the confidence interval of the observed biomass to the prediction interval of the new model.

Finally, we sought to determine how sensitive the predictions of the most parsimonious model were to variation in the input values. Using the most parsimonious model with a fixed value for larval abundance (which is known from $2 \mathrm{yr}$ prior), we re-ran the model with variations of the observed values for fall condition and $t_{\text {ice: }}$ good/late $(+1 \mathrm{SD})$, medium (mean), and poor/early $(-1 \mathrm{SD})$. We also re-ran the model using very early values for $t_{\text {ice }}(-2 \mathrm{SD})$ because a value of this magnitude occurred in 2010. No values of $+2 \mathrm{SD}$ for $t_{\text {ice }}$ have been observed since the early 1970s and, given the projected warming trend on the NL shelf (Han et al. 2015), it would be unrealistic to expect such late dates of ice retreat. We compared the predicted values of these 9 possible scenarios with the actual predicted value.

\subsubsection{Forecasts}

In addition to a better understanding of factors that influence capelin biomass, this work is also intended to inform management. Depending on the variables in the model, we used capelin larval abundance and larval prey density (i.e. Pseudocalanus spp.) in 2016 and 2017 to produce capelin biomass forecasts for 2018 and 2019 respectively. We used the fall condition index from 2017 to inform the capelin biomass forecast for 2018 and used average fall condition over the data series to forecast capelin biomass in 2019. Similarly, we assessed the ice charts to determine $t_{\text {ice }}$ for 2018 and used the average value of the $t_{\text {ice }}$ over the time series (79 d) to forecast capelin biomass in 2019. We present 2018 capelin biomass as a 'forecast' because the 2018 estimates of biomass are currently unavailable.

We performed all analyses in program R v.3.3.3 (R Core Team 2017) using RStudio v.1.0.136. Bayesian analyses were performed using JAGS (Plummer 2003) within the $R$ environment using packages
'R2jags' v.0.5-7 (Su \& Yajima 2012) and 'rjags' v.4-6 (Plummer 2012). Mixing of chains, autocorrelation, comparisons of the priors/posteriors, and posterior values were assessed using functions produced by Highland Statistics (Zuur et al. 2013).

\section{RESULTS}

Based on the annual offshore spring acoustic surveys, the capelin biomass index (hereafter, capelin biomass) varied between 22 and 982 thousand tonnes (kt) from 2003-2017. For most years, capelin biomass ranged from $98-300 \mathrm{kt}$; all 3 of the highest values were from 2013-2015 (660-980 kt) with the lowest capelin biomass in 2010 (22 kt).

The CSAM3 model, which included larval abundance, $t_{\text {ice, }}$ and fall condition, received considerable support and explained $68 \%$ of the variance (Table 3 ). For CSAM3, many of the yearly estimates were very similar to the observed biomass values and all years were captured except 2014, i.e. the estimated capelin biomass in 2014 did not fall within the credible interval of this model although the fitted trend was correct (Fig. 3A). The CSAM2 model received moderate support but failed to capture 2013-2014. The CS1 and CSAM1 models received considerably less support than the CSAM3 model, while the AM1, CS0, and AM0 models received very little support (Table 3). These models failed to capture between 2 and 5 years of capelin biomass. None of the models under consideration had a $\triangle \mathrm{DIC}>10$. As indicated by the MSPE scores, the ability of the models to predict out-of-sample observations did not always align with the DIC scores, but CSAM3 still had the best predictive ability of all of the models based on the MSPE

Table 3. Model selection statistics for the capelin biomass models considered in Table 2. DIC: deviance information criterion; $\triangle \mathrm{DIC}$ : difference between change in DIC from the most parsimonious model; MSE: mean squared error (Gelman et al. 2014). $\mathrm{R}^{2}$ and associated standard deviation (SD) are for Bayesian analyses (Gelman et al. 2018). Lower values of MSE indicate greater predictive ability

\begin{tabular}{|lccccc|}
\hline Model & DIC & $\Delta$ DIC & MSE & $\mathrm{R}^{2}$ & SD \\
\hline CSAM3 & 23.2 & 0.0 & 0.57 & 0.68 & 0.12 \\
CSAM2 & 25.8 & 2.6 & 0.70 & 0.64 & 0.14 \\
CS1 & 29.8 & 6.6 & 1.21 & 0.53 & 0.15 \\
CSAM1 & 30.3 & 7.1 & 0.63 & 0.49 & 0.15 \\
AM1 & 32.2 & 9.0 & 0.92 & 0.47 & 0.17 \\
CS0 & 32.9 & 9.7 & 0.70 & 0.38 & 0.17 \\
AM0 & 33.1 & 9.9 & 0.91 & 0.17 & 0.06 \\
\hline
\end{tabular}



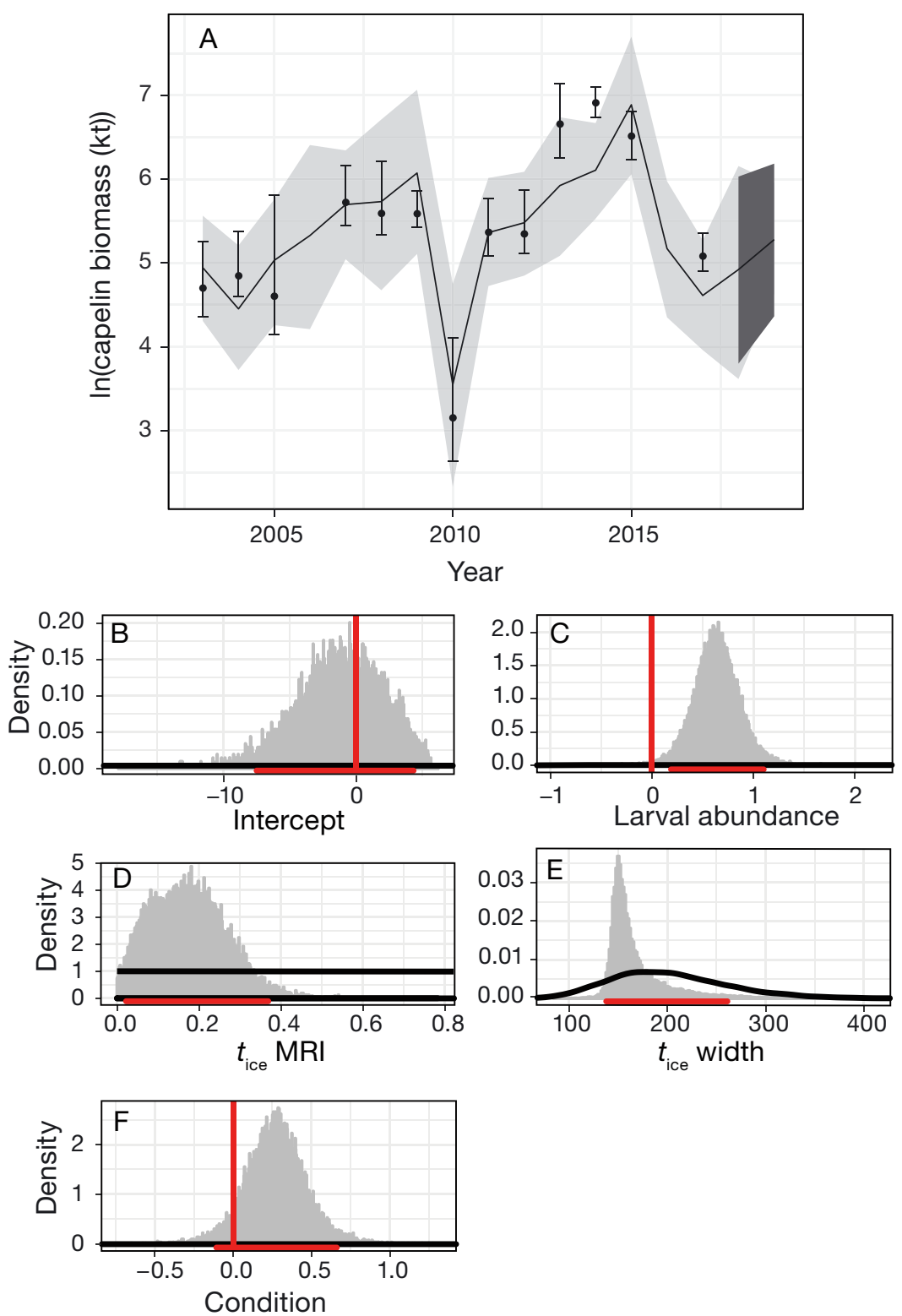

Fig. 3. Results for the capelin cohort strength/mortality model (CSAM3) including (A) the $95 \%$ credible (light grey) and $80 \%$ prediction intervals (dark grey) for expected values of capelin biomass (solid line) and observed values $( \pm 95 \%$ confidence intervals) and $(\mathrm{B}-\mathrm{F})$ prior (black) and posterior distributions (grey), and the $95 \%$ credible intervals (red rug plot) of the parameter estimates. For reference, zero (red vertical line) is indicated except for the timing of the retreat of sea ice $\left(t_{\text {ice }}\right)$ parameters for which differences from zero are not meaningful. For $t_{\text {ice }}$ the maximal rate of increase (MRI) and width variables were back-transformed to the original scale to improve ease of interpretation

scores (Table 3). We subsequently examined the posterior values of the parameter estimates of CSAM3 to determine the relative importance of different variables and to further interpret the DIC table.

The posterior distribution of parameters of CSAM3, the most parsimonious model, showed that model par- simony was largely driven by larval abundance and $t_{\text {ice }}$ while fall condition explained a lesser amount of the interannual variability in capelin biomass (Fig. 3B-F). For CSAM3, the $95 \%$ credible intervals of the posterior values for larval abundance and $t_{\text {ice }}$ (maximal rate of increase) did not overlap zero, suggesting a strong effect (Fig. 3C-E, Table 4). The median value of the posterior distributions suggests a 0.63 increase in capelin biomass for a unit increase in larval abundance while the $t_{\text {ice }}$ dome was centered (width/2) at $84 \mathrm{~d}$, indicating that, according to this model, maximum capelin biomass occurs when the sea ice retreat begins in mid-to-late March (Fig. 3C-E, Fig. 4). The other variables under consideration in this model set, including larval prey availability density (Pseudocalanus spp.; CS1) and fall capelin condition (AM1, CSAM1, and CSAM3), had a positive but weaker relationship with capelin biomass, i.e. the $2.5 \%$ credible limit of the posterior values was less than zero.

The jack-knife cross-validation indicates that the predictive performance of the most parsimonious model, CSAM3, is robust for most years. The average percent difference between predicted and observed values was $13.0 \pm 13.4 \%$ (Fig. 5). Percent differences ranged from $<1$ to $20 \%$ for all years except $2010(52.6 \%)$, which was the only year with extremely low capelin biomass.

The predictions of the CSAM3 model are reasonably insensitive to deviations in $t_{\text {ice }}$ and fall capelin condition. When the input values are within $1 \mathrm{SD}$ of the average, the results are very similar to the predicted biomass values. Only very early $t_{\text {ice }}$ combined with medium or poor fall capelin condition results in statistical differences from the predicted value (Fig. 6). The CSAM3 model forecasts capelin biomass will increase in 2018 (median = $137 \mathrm{kt}, 80 \%$ prediction interval $=44-407 \mathrm{kt}$ ) and again in 2019 (median $=197 \mathrm{kt}, 80 \%$ prediction inter$\mathrm{val}=80-493 \mathrm{k})$ compared to $2017($ median $=101 \mathrm{kt}$, $95 \%$ credible interval $=53-197$ kt; Fig. 3A) . 
Table 4. Posterior parameter estimates $( \pm \mathrm{SE})$ with associated variables and 2.5 and $97.5 \%$ credible values for the capelin cohort strength + adult mortality model (CSAM3), the most parsimonious model (see Table 2 for model structure). $\beta$ and $\theta$ reflect a linear relationship with the associated variable while $\delta$ and $\eta$ are parameters in the dome-shaped model. $t_{\text {ice: }}$ timing of the retreat of sea ice

\begin{tabular}{|llccccc|}
\hline \multirow{2}{*}{ Parameters } & Associated variables & Mean & SE & $2.5 \%$ & Median & $97.5 \%$ \\
\hline$\alpha$ & Intercept & -1.05 & 3.13 & -7.68 & -0.89 & 4.38 \\
$\beta$ & Larval abundance & 0.63 & 0.23 & 0.18 & 0.63 & 1.09 \\
$\delta$ & $t_{\text {ice }: \text { max. rate of increase }}$ & 17.11 & 9.30 & 2.27 & 16.43 & 36.96 \\
$\eta$ & $t_{\text {ice }}:$ width & 1.68 & 0.31 & 1.37 & 1.57 & 2.60 \\
$\theta$ & Condition & 0.27 & 0.19 & -0.10 & 0.27 & 0.66 \\
\hline
\end{tabular}

the regulation of capelin biomass. The CSAM3 model offers a substantial improvement over the AM0 and CS0 models by combining cohort strength, fall capelin condition, and $t_{\text {ice }}$ to forecast capelin biomass. Essentially, higher larval abundance in July and August 2 years prior improved adult condition the preceding fall, and a retreat of sea ice in mid-to-late March of the

\section{DISCUSSION}

Forage fish populations are known to fluctuate dramatically and have consequently been difficult to forecast (Pikitch et al. 2012). By using readily available indices of capelin cohort strength, adult fall condition, and adult mortality $\left(t_{\text {ice }}\right)$, we were able to explain $68 \%$ of the variation in Newfoundland capelin stock biomass. Further, the stock biomass can be predicted 1-2 management cycles in advance, providing valuable information for fisheries management.

These results extend earlier research that found the timing of sea ice retreat, i.e. $t_{\text {ice }}$ (Buren et al. 2014a; AM0), and the abundance of emergent larvae (Murphy et al. 2018; CS0) play an important role in

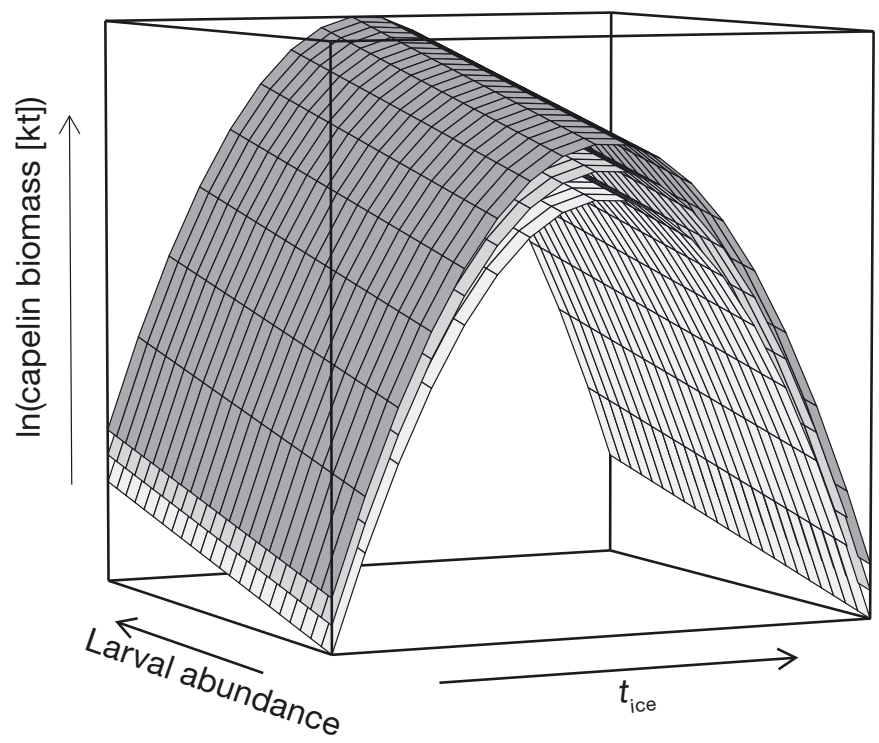

Fig. 4. Graphical representation of the cohort strength + adult mortality model (CSAM3) at 3 levels of the fall body condition of pre-spawning capelin (light grey: minimum condition observed; mid-grey: average condition observed; dark grey: maximum condition observed). $t_{\text {ice: }}$ timing of the retreat of sea ice

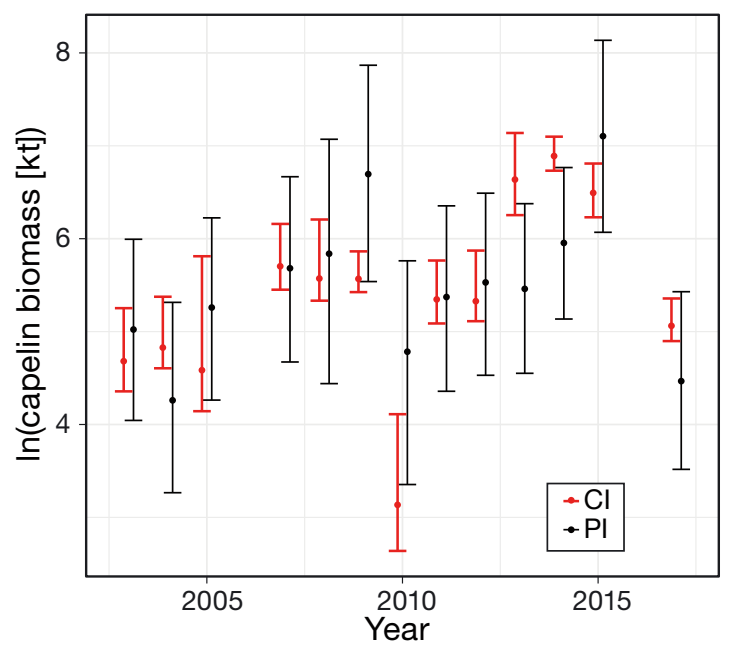

Fig. 5. Comparison of the point estimate and $95 \%$ confidence intervals (CI) of the observed capelin biomass by year (20032017) and the point estimate and $80 \%$ prediction intervals (PI) generated by a leave-one-out jack-knife validation

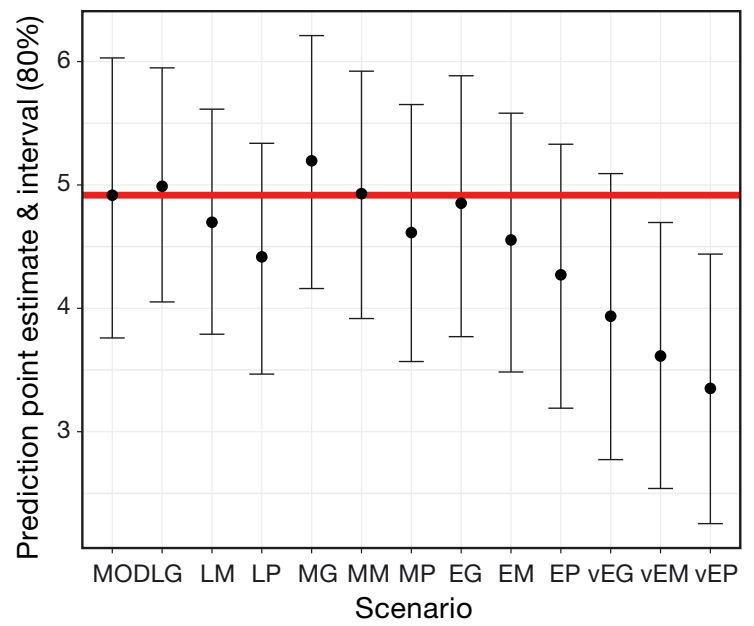

Fig. 6. Sensitivity of model predictions to deviations from the input values. Various scenarios were compared with the cohort strength + adult mortality model (CSAM3) model (MOD). Scenarios included combinations of timing of the retreat of sea ice (L: late; M: medium; E: early; vE: very early) and condition (G: goodi M: medium; P: poor). The horizontal red line indicates the prediction point estimate of the CSAM3 model 
current year produced the highest annual capelin biomass. This model also had the best predictive ability of the models we considered.

\subsection{Bottom-up regulation}

Capelin condition in the fall has not previously been considered as a factor influencing capelin population dynamics. Although fall condition had a weak, positive influence on capelin biomass, fall condition was the only difference between the CSAM3 and CSAM2 models. This suggests that prey availability for adult capelin in the fall before the overwintering period is a driver of capelin survival. In the Newfoundland region, capelin diet in the fall and spring is dominated by Calanus spp. copepods (C. finmarchicus, C. glacialis, and C. hyperboreus) (Dalpadado \& Mowbray 2013, F. Mowbray unpubl. data). However, since 2015 there has been a shift in the zooplankton community on the Newfoundland shelf from one dominated by large bodied copepods like $C$. finmarchicus to one dominated by medium-sized copepods like Pseudocalanus spp. (Pepin et al. 2017). This recent change in prey community composition may have a detrimental effect on the condition of adult capelin in the fall and, ultimately, on capelin survival. The importance of bottom-up factors (e.g. prey availability) for capelin survival is consistent with other studies that have shown forage fish populations are largely driven by bottomup forces (Schwartzlose \& Alheit 1999, Cury et al. 2000, Vilhjálmsson 2002, Chavez et al. 2003, Alheit \& Niquen 2004, Pikitch et al. 2012, Boldt et al. 2018).

Sea ice extent is projected to decline in the coming decades due to global climate change (Han et al. 2015) which may cause sea ice to retreat earlier. Given the well-known influence of sea ice on the spring bloom and zooplankton population dynamics (Wu et al. 2007, Wassmann 2011), earlier $t_{\text {ice }}$ will likely negatively influence pre-spawning capelin through match/mis-match dynamics by affecting the abundance of its prey (Cushing 1990). This may already be occurring with recent observed changes in zooplankton phenology in the Newfoundland shelf ecosystem (Pepin et al. 2017).

While there were signs of a potential recovery in capelin in 2013-2015 with abundance estimates 25\% of those pre-1991, capelin abundance decreased $70 \%$ in 2017 to levels similar to the late 2000s (DFO 2018). Although a modest increase in capelin biomass is predicted by our model for 2018 and 2019, the environmental trends of a changing zooplankton community and its associated influence on capelin condition, as well as earlier ice retreat, suggests that declines in capelin biomass are likely beyond this time frame. In short, the demographic, morphological, and ecosystem indices relevant to capelin are low, and a precautionary management approach is warranted.

\subsection{Management implications}

Fisheries management involves assessing the likelihood and impact of different scenarios, especially in the near-term (Payne et al. 2017, Scales et al. 2017, Dietze et al. 2018). For improving management of capelin, this model has a number of desirable features. DFO in the Newfoundland region traditionally holds annual scientific meetings for capelin in March in order to determine the status of the capelin stock and to provide advice to the Canadian Federal Fisheries Minister on TAC (Fig. 2). One advantage of the CSAM3 model is that 2 of the 3 explanatory data series are available for the stock assessment (Table 1). For the third variable, $t_{\text {ice, }}$ we can monitor the spring ice conditions and use a variety of scenarios based on historical patterns of sea ice retreat to provide advice on a provisional TAC that can be revised in early spring (April) when the final estimate of $t_{\text {ice }}$ is available. Another advantage is that the CSAM3 model is robust to modest deviations from the observed values for $t_{\text {ice }}$ and fall condition (Fig. 6). The CSAM3 model also has the desirable feature of underestimating capelin biomass in the few years when estimates of biomass are high (Fig. 3A), as seen in 2013 and 2014, so advice on TAC will be conservative. Finally, the CSAM3 model can provide an early warning for years when capelin stock biomass is forecasted to be low due to a very early ice retreat.

\subsection{Sources of uncertainty}

Like most forage fish, capelin are sensitive to environmental conditions and, as such, capelin populations tend to be highly stochastic (process variation; Pikitch et al. 2012). This process variation is compounded by sampling variation, which is likely high in the data used to develop the capelin forecast model due to the incomplete spatial coverages of both the spring acoustic survey and the larval monitoring program. The spring acoustic survey covers the main capelin nursery area (Div. 3KL; Fig. 1) which encompasses a large proportion of, but not the entire distributional area of the Newfoundland capelin stock (Mowbray 2013). Further, the larval monitoring program is 
based at only one inshore area in one bay although previous research found a high degree of synchrony of larval emergence at Newfoundland beaches (Frank \& Leggett 1981a, Nakashima 1996). Nevertheless, the CSAM3 model explains a considerable amount of the variation in these data for 2 putative reasons. First, in terms of cohort strength, the physical environment is important for the early life history of capelin (Leggett et al. 1984) and oceanographic/climatic conditions are similar in the nearshore areas along the east coast of Newfoundland. Second, large-scale environmental variables on the Newfoundland shelf have been related to adult capelin mortality (Buren et al. 2014a). All models tested, however, failed to capture the very high capelin biomass observed in 2014 and all other models except CSAM3 failed to capture 2013. Additional or alternative variables may be needed to better capture these years.

Alternatively, data that could be included in the capelin forecast model are phytoplankton bloom dynamics and production of Calanus spp., which may be more direct measures of environmental conditions for capelin rather than using $t_{\text {ice }}$ as a proxy for primary and secondary production. We did conduct extensive exploratory analyses to determine if we could further refine the $t_{\text {ice }}$ variable by examining total sea ice concentration, stage of ice development, and associated partial concentration, but without success. We also sought to find a relationship between $t_{\text {ice }}$ and sea ice extent (SIE) because statistical projections for SIE have been developed (Han et al. 2015) with clear advantages from a management perspective. However, there was no relationship between $t_{\text {ice }}$ and SIE or between SIE and capelin biomass. Finally, top-down forces (i.e. fisheries and predation) can interact with bottom-up forces to drive population dynamics (Essington et al. 2015, Gjøsæter et al. 2015, Jacobsen \& Essington 2018, Stige et al. 2018), which is an important consideration for management of a commercial forage fish like capelin (Gjøsæter et al. 2015). The potential impacts of fishing and predation mortality should be considered in future model iterations.

\section{CONCLUSIONS}

Sustainability of forage fish stocks is important for local economies (DFO 2017), and capelin, as a keystone forage fish, play a pivotal role in the Newfoundland ecosystem as important food for seabirds, cod, seals, and whales (Montevecchi 2007, Buren et al. 2014b, Stenson et al. 2016, J. Lawson \& G. Stenson unpubl. data). Given the depressed state of the Newfoundland capelin stock in the NW Atlantic, robust tools are required to manage this stock. We showed that simple proxies for adult mortality (i.e. $t_{\text {ice }}$ and fall capelin condition) and cohort strength (i.e. larval abundance) can explain $68 \%$ of the variation in capelin biomass. The approach we developed can provide robust scientific advice for fisheries managers and stakeholders on the projected state of the Newfoundland capelin stock.

Acknowledgements. This work was supported by the Department of Fisheries and Oceans, specifically through the Strategic Program for Ecosystem-Based Research and Advice (Principal investigators: A.D.B. and P.M.R.). We thank the staff at the Northwest Atlantic Fisheries Centre, especially the Pelagics Section, who provided support and collected the data used in this study as well as Gary Maillet and Pierre Pepin for the AZMP data. Aaron Adamack reviewed a previous version of the manuscript. Eric Pedersen, Mariano Koen-Alonso, and Andrew Parnell provided useful statistical advice. We also thank the Marine Mammals section for supporting this project.

\section{LITERATURE CITED}

Alder J, Campbell B, Karpouzi V, Kaschner K, Pauly D (2008) Forage fish: from ecosystems to markets. Annu Rev Environ Resour 33:153-166

Alheit J, Niquen M (2004) Regime shifts in the Humboldt Current ecosystem. Prog Oceanogr 60:201-222

*Boldt JL, Thompson M, Rooper CN, Hay DE and others (2018) Bottom-up and top-down control of small pelagic forage fish: factors affecting age-0 herring in the Strait of Georgia, British Columbia. Mar Ecol Prog Ser, doi: 10.3354/meps12485

Bolker BM (2008) Ecological models and data in R. Princeton University Press, Princeton, NJ

Buren AD, Koen-Alonso M, Montevecchi WA (2012) Linking predator diet and prey availability. Mar Ecol Prog Ser 445:25-35

Buren AD, Koen-Alonso M, Pepin P, Mowbray F and others (2014a) Bottom-up regulation of capelin, a keystone forage species. PLOS ONE 9:e87589

Buren AD, Koen-Alonso M, Stenson GB (2014b) The role of harp seals, fisheries and food availability in driving the dynamics of northern cod. Mar Ecol Prog Ser 511: 265-284

Buren AD, Murphy HM, Adamack AT, Davoren GK and others (2019) The collapse and continued low productivity of a keystone forage fish species. Mar Ecol Prog Ser, doi:10.3354/meps12924

Carscadden JE, Vilhjálmsson H (2002) Capelin-What are they good for? Introduction. ICES J Mar Sci 59:863-869

Carscadden J, Frank K, Leggett W (2000) Evaluation of an environment-recruitment model for capelin (Mallotus villosus). ICES J Mar Sci 57:412-418

Carscadden J, Frank K, Leggett W (2001) Ecosystem changes and the effects on capelin (Mallotus villosus), a major forage species. Can J Fish Aquat Sci 58:73-85

Chavez FP, Ryan J, Lluch-Cota SE, Niquen M (2003) From 
anchovies to sardines and back: multidecadal change in the Pacific Ocean. Science 299:217-221

Cury P, Bakun A, Crawford RJ, Jarre A, Quinones RA, Shannon LJ, Verheye HM (2000) Small pelagics in upwelling systems: patterns of interaction and structural changes in "wasp-waist" ecosystems. ICES J Mar Sci 57:603-618

Cushing D (1990) Plankton production and year-class strength in fish populations: an update of the match/mismatch hypothesis. Adv Mar Biol 26:249-293

Dalley EL, Anderson JT, De Young B (2002) Atmospheric forcing, larval drift, and recruitment of capelin (Mallotus villosus). ICES J Mar Sci 59:929-941

Dalpadado P, Mowbray F (2013) Comparative analysis of feeding ecology of capelin from two shelf ecosystems, off Newfoundland and in the Barents Sea. Prog Oceanogr 114:97-105

* Davoren GK, Montevecchi WA (2003) Signals from seabirds indicate changing biology of capelin stocks. Mar Ecol Prog Ser 258:253-261

DeYoung B, Rose G (1993) On recruitment and distribution of Atlantic cod (Gadus morhua) off Newfoundland. Can J Fish Aquat Sci 50:2729-2741

ํ.DFO (Fisheries and Oceans Canada) (2017) Capelin Newfoundland \& Labrador Region 2+3 (Capelin Fishing Areas 1-11). www.dfo-mpo.gc.ca/fm-gp/peches-fisheries/ifmpgmp/capelin-area1-11-zone-capelan/index-eng.htm\#toc 1.0 (accessed 1 Jun 2018)

DFO (2018) Assessment of capelin in SA2 and Divs. 3KL in 2017. DFO Can Sci Advis Sec Sci Advis Rep 2018/030

Dietze MC, Fox A, Beck-Johnson LM, Betancourt JL and others (2018) Iterative near-term ecological forecasting: needs, opportunities, and challenges. Proc Natl Acad Sci USA 115:1424-1432

Dwyer K, Buren A, Koen-Alonso M (2010) Greenland halibut diet in the Northwest Atlantic from 1978 to 2003 as an indicator of ecosystem change. J Sea Res 64:436-445

Essington TE, Moriarty PE, Froehlich HE, Hodgson EE and others (2015) Fishing amplifies forage fish population collapses. Proc Natl Acad Sci USA 112:6648-6652

FAO (2006) State of world fisheries and aquaculture. FAO, Rome

Frank KT, Leggett WC (1981a) Prediction of egg development and mortality rates in capelin (Mallotus viliosus) from meteorological, hydrographic, and biological factors. Can J Fish Aquat Sci 38:1327-1338

Frank KT, Leggett WC (1981b) Wind regulation of emergence times and early larval survival in capelin (Mallotus villosus). Can J Fish Aquat Sci 38:215-223

Gelman A, Rubin DB (1992) Inference from iterative simulation using multiple sequences. Stat Sci 7:457-472

* Gelman A, Hwang J, Vehtari A (2014) Understanding predictive information criteria for Bayesian models. Stat Comput 24:997-1016

Gelman A, Goodrich B, Gabry J, Vehtari A (2018) R-squared for Bayesian regression models. Am Stat,

* Gjøsæter H, Bogstad B, Tjelmeland S, Subbey S (2015) A retrospective evaluation of the Barents Sea capelin management advice. Mar Biol Res 11:135-143

Gulka J, Carvalho PC, Jenkins E, Johnson K, Maynard L, Davoren GK (2017) Dietary niche shifts of multiple marine predators under varying prey availability on the northeast Newfoundland coast. Front Mar Sci 4:324

Han G, Colbourne E, Pepin P, Xie Y (2015) Statistical projections of ocean climate indices off Newfoundland and Labrador. Atmos-Ocean 53:556-570
Hilborn R, Walters CJ (1992) Quantitative fisheries stock assessment: choice, dynamics and uncertainty. Chapman and Hall, New York, NY

Hobbs NT, Geremia C, Treanor J, Wallen R, White P, Hooten MB, Rhyan JC (2015) State space modeling to support management of brucellosis in the Yellowstone bison population. Ecol Monogr 85:525-556

* Hooten MB, Hobbs N (2015) A guide to Bayesian model selection for ecologists. Ecol Monogr 85:3-28

ICES (2016a) Capelin (Mallotus villosus) in subareas 5 and 14 and Division 2.a west of $5^{\circ} \mathrm{W}$ (Iceland and Faroes Grounds, East Greenland, Jan Mayen Area). ICES Advice on Fishing Opportunities, Catch, and Effort (cap.27.2a514). ICES, Copenhagen

ICES (2016b) Capelin (Mallotus villosus) in subareas 1 and 2 (Northeast Arctic), excluding Division 2.a west of $5^{\circ} \mathrm{W}$ (Barents Sea capelin). ICES Advice on Fishing Opportunities, Catch, and Effort (Book 3). ICES, Copenhagen

Jacobsen NS, Essington TE (2018) Natural mortality augments population fluctuations of forage fish. Fish Fish 19:791-797

* Le Cren E (1951) The length-weight relationship and seasonal cycle in gonad weight and condition in the perch (Perca fluviatilis). J Anim Ecol 20:201-219

* Leggett W, Frank K, Carscadden J (1984) Meteorological and hydrographic regulation of year-class strength in capelin (Mallotus villosus). Can J Fish Aquat Sci 41: 1193-1201

Link JS (2002) What does ecosystem-based fisheries management mean? Fisheries (Bethesda, Md) 27:18-21

Mac Nally R, Duncan RP, Thomson JR, Yen JD (2018) Model selection using information criteria, but is the 'best' model any good? J Appl Ecol 55:1441-1444

* Montevecchi WA (2007) Binary dietary responses of northern gannets Sula bassana indicate changing food web and oceanographic conditions. Mar Ecol Prog Ser 352:213-220

Mowbray FK (2013) Some results from spring acoustic surveys for capelin (Mallotus villosus) in NAFO Division 3L between 1982 and 2010. DFO Can Sci Advis Sec Res Doc 2012/143

Mowbray FK (2014) Recent spring offshore acoustic survey results for capelin, Mallotus villosus, in NAFO Division 3L. DFO Can Sci Advis Sec Res Doc 2013/040

Murphy HM, Pepin P, Robert D (2018) Re-visiting the drivers of capelin recruitment in Newfoundland since 1991. Fish Res 200:1-10

Nakashima BS (1996) The relationship between oceanographic conditions in the 1990s and changes in spawning behaviour, growth and early life history of capelin (Mallotus villosus). NAFO Sci Coun Studies 24:55-68

Nakashima B, Mowbray F (2014) Capelin (Mallotus villosus) recruitment indices in NAFO Division 3KL. DFO Can Sci Advis Sec Res Doc 2013/091

Nakashima BS, Wheeler JP (2002) Capelin (Mallotus villosus) spawning behaviour in Newfoundland waters - the interaction between beach and demersal spawning. ICES J Mar Sci 59:909-916

* Obradovich SG, Carruthers EH, Rose GA (2014) Bottom-up limits to Newfoundland capelin (Mallotus villosus) rebuilding: the euphausiid hypothesis. ICES J Mar Sci 71:775-783

Olden JD, Jackson DA, Peres Neto PR (2002) Predictive models of fish species distributions: a note on proper validation and chance predictions. Trans Am Fish Soc 131:329-336 
Payne MR, Hobday AJ, MacKenzie BR, Tommasi D and others (2017) Lessons from the first generation of marine ecological forecast products. Front Mar Sci 4:289

Pedersen EJ, Thompson PL, Ball RA, Fortin MJ and others (2017) Signatures of the collapse and incipient recovery of an overexploited marine ecosystem. R Soc Open Sci 4:170215

Pepin P, Maillet G, Fraser S, Robar A, Shears T, Redmond G (2017) Optical, chemical and biological oceanographic conditions on the Newfoundland and Labrador shelf during 2014-2015. DFO Can Sci Advis Sec Res Doc 2017/009

Pikitch E, Santora C, Babcock E, Bakun A and others (2004) Ecosystem-based fishery management. Science 305: 346-347

Pikitch E, Boersma PD, Boyd I, Conover D and others (2012) Little fish, big impact: managing a crucial link in ocean food webs. Lenfest Ocean Program, Washington, DC

Plummer M (2003) JAGS: a program for analysis of Bayesian graphical models using Gibbs sampling. In: Hornik K, Leisch F, Zeileis A (eds) DSC 2003: proceedings of the $3^{\text {rd }}$ international workshop on distributed statistical computing, 20-22 March 2003, Vienna. Austrian Association for Statistical Computing, Vienna

Plummer M (2012) JAGS: just another Gibbs sampler. Astrophysics Source Code Library. http://ascl.net/1209.002

R Core Team (2017) R: a language and environment for statistical computing. R Foundation for Statistical Computing, Vienna

Rice J (2002) Changes to the large marine ecosystem of the Newfoundland-Labrador shelf. In: Skjoldal HR, Sherman K (eds) Large marine ecosystems, Vol 10. Elsevier, Amsterdam, p 51-103

Scales KL, Hazen EL, Maxwell SM, Dewar H and others (2017) Fit to predict? Eco informatics for predicting the catchability of a pelagic fish in near real time. Ecol Appl 27:2313-2329

Schwartzlose R, Alheit J (1999) Worldwide large-scale fluctuations of sardine and anchovy populations. Afr J Mar Sci 21:289-347

Shackell NL, Shelton PA, Hoenig JM, Carscadden JE (1994) Age-and sex-specific survival of northern Grand Bank

Editorial responsibility: Elliott Hazen, Pacific Grove, California, USA capelin (Mallotus villosus). Can J Fish Aquat Sci 51: 642-649

Spiegelhalter DJ, Best NG, Carlin BP, Van Der Linde A (2002) Bayesian measures of model complexity and fit. J R Stat Soc Series B Stat Methodol 64:583-639

Stenson GB, Buren AD, Koen-Alonso M (2016) The impact of changing climate and abundance on reproduction in an ice-dependent species, the Northwest Atlantic harp seal, Pagophilus groenlandicus. ICES J Mar Sci 73:250-262

Stige LC, Kvile KØ, Bogstad B, Langangen Ø (2018) Predator prey interactions cause apparent competition between marine zooplankton groups. Ecology 99:632-641

Su YS, Yajima M (2012) R2jags: a package for running jags from R. R package version 003-08. http://cran.r-project. org/package $=$ R2jags

Taylor AH, Allen JI, Clark PA (2002) Extraction of a weak climatic signal by an ecosystem. Nature 416:629-632

Templeman W (1948) The life history of the capelin (Mallotus villosus OF Muller) in Newfoundland waters. Res Bull Nfld Gov Lab 17:1-151

*Vilhjálmsson H (2002) Capelin (Mallotus villosus) in the Iceland-East Greenland-Jan Mayen ecosystem. ICES J Mar Sci 59:870-883

Wassmann P (2011) Arctic marine ecosystems in an era of rapid climate change. Prog Oceanogr 90:1-17

Wilson CJ, Murphy HM, Bourne C, Pepin P, Robert D (2018) Feeding ecology of autumn-spawned Atlantic herring (Clupea harengus) larvae in Trinity Bay, Newfoundland: Is recruitment linked to main prey availability? J Plankton Res 40:255-268

Wu Y, Peterson IK, Tang CC, Platt T, Sathyendranath S, Fuentes-Yaco C (2007) The impact of sea ice on the initiation of the spring bloom on the Newfoundland and Labrador shelves. J Plankton Res 29:509-514

* Zuur AF, Ieno EN, Elphick CS (2010) A protocol for data exploration to avoid common statistical problems. Methods Ecol Evol 1:3-14

Zuur AF, Hilbe JM, Ieno EN (2013) A beginner's guide to GLM and GLMM with R: a frequentist and Bayesian perspective for ecologists. Highland Statistics Limited, Newburgh

Submitted: July 16, 2018; Accepted: March 12, 2019 Proofs received from author(s): April 25, 2019 